\title{
O puerpério como espaço educativo para o cuidado mãe e bebê
}

\author{
Cristiane Rodrigues da Rocha \\ crica.rocha@hotmail.com \\ Inês Maria Meneses dos Santos \\ inesmeneses@gmail.com
}

Isabeli Fragoso da Conceição

isabeli.fragosoc@gmail.com

\section{Leila Rangel da Silva}

rangel.leila@gmail.com

\section{Mayara Tereza de Carvalho}

mayaracarvalho@globo.com

Universidade Federal do Estado do Rio de Janeiro | Brasil

\section{Resumo}

0 presente relato de experiência tem como objetivo expor e discutir as ações de enfermagem com vistas a aumentar a competência da mulher para o seu autocuidado no período puerperal e cuidado do filho recém-nascido. Na população alvo deste projeto, que são as mulheres internadas no alojamento conjunto do Hospital Universitário Gaffrèe e Guinle, foi empregado entrevistas com foco nos conhecimentos das mulheres sobre o processo puerperal e realizado práticas de ações educativas individuais e coletivas. Obteve-se como principais resultados maior sucesso na amamentação, diminuição pela instituição de compra de leite industrializado para os recém-nascidos, diminuição do período de internação, menor retorno com problemas na amamentação e por gravidez indesejada. Concluímos que uma assistência individualizada que valorize os aspectos emocionais e socioculturais das puérperas, que as torne protagonistas do seu próprio cuidado reflete na sua saúde, do bebê e da família.

\section{Palavras-chave}

Puerpério. Educação em Saúde. Enfermagem Obstétrica. 


\section{Introdução}

O projeto de extensão denominado "Espaço Educativo para o Cuidado de Mãe e Bebê" está vinculado à Pró-reitora de Extensão e Cultura da Universidade Federal do Estado do Rio de Janeiro. Foi criado em 2010 por docentes que pertencem ao Departamento de Enfermagem Materno-Infantil da Escola de Enfermagem Alfredo Pinto. O projeto tem como estímulo para seu nascedouro o Curso de Humanização de Parto e Nascimento, que uma das autoras realizou em 1996, nas Maternidades e Casas de Parto no Japão. E neste cenário, aprendeu que é preciso resgatar o novo a partir do antigo, principalmente quando pensarmos nas questões de atenção à saúde primária e as práticas milenares.

No ano de 2009 concorremos ao Projeto Follow-Up, do Governo japonês, para montarmos uma sala denominada de "Espaço educativo para o cuidado de mãe e bebê". Com a verba recebida do projeto e com o apoio da chefia de enfermagem e médica à época, foi reformado um almoxarifado dentro do Hospital Universitário Gaffrée e Guinle, possibilitando espaço necessário para desenvolvimento dos atendimentos individualizados e local centralizado para discussão de casos com os bolsistas e alunos do Curso de Graduação em Enfermagem.

Após retornar ao Brasil, a professora replicou essa experiência no ensino, na pesquisa e na extensão. Na extensão, essas experiências tem sido aplicadas no atendimento à mulher no pós-parto, como no trabalho com o aleitamento materno e o cuidado com o recém-nascido, principalmente focando no autocuidado da mulher no período puerperal e cuidados primários de saúde do recém-nascido.

Consideramos que o autocuidado é a escolha, livre e autônoma, de ferramentas que irão promover uma atenção, bem como a ação do indivíduo sobre si mesmo para manter uma qualidade de vida de maneira responsável. É adotar medidas de prevenção de doenças e controlar fatores de risco, buscar hábitos de vida saudáveis e melhorar o estilo de vida (COSTA et al., 2013).

$\mathrm{Na}$ busca da prevenção das doenças a mulher no puerpério deve receber orientações de acordo com a necessidade expressada pela fala e/ou pela observação dos profissionais. As orientações direcionadas às mulheres tem como retorno a melhora das condições de autocuidado para a promoção e preservação da saúde tal como a prevenção 
de agravos (PEREIRA; GRADIM, 2014).

0 pós-parto é um período em que ocorre a interação do binômio mãe-filho, através do cuidado ao recém-nascido (RN). Todo esse processo gradual e contínuo começa no alojamento conjunto, onde a mãe do RN saudável possui o direito, garantido por lei, de permanecer com seu filho 24 horas por dia, no mesmo âmbito hospitalar até a alta (BRASIL, 1990). É o momento ideal para promover orientações relativas aos cuidados com o filho, incentivar a amamentação e facilitar o vínculo (BRASIL, 2014).

O puerpério é um período carregado de mitos, crenças e costumes, assim, a todo o momento é preciso estar atento quando cuidamos de puérperas e recém-nascidos. É neste período que estreitamos laços no cuidado (enfermeira-cliente-família) onde é preciso respeitar às crenças, mitos, ritos, saberes e práticas culturais que a mãe traz apreendido de gerações e que não podem ser desvalorizadas (ACOSTA et al., 2012).

A cultura é entendida como um conjunto de significados, crenças, valores, imagens, imaginários e símbolos nos quais somos inseridos diariamente, delineados pela compreensão de nosso viver. O âmbito familiar traz consigo conhecimentos e experiências pertinentes a sua vivência, ao exercerem cuidados familiares, perpassam mitos, crenças, valores e tabus aceitos por elas. As orientações repassadas às puérperas no âmbito de convencimento de mudança do pensamento, no qual envolve a cultura familiar, deve ser de tal forma que ela possa compreender os riscos e benefícios, as vantagens e desvantagens, e sendo indispensável a compreensão, por parte dos profissionais de saúde, do significado cultural que as pessoas empregam em suas ações (MIRANDA et al, 2015).

Neste sentido, entendemos que se faz necessário integrar ensino e extensão com a execução deste Projeto, já que ao mesmo tempo em que iremos cuidar de mulheres no pós-parto e seus filhos, estaremos ensinando aos alunos cuidar do outro de forma individualizada e respeitando o contexto sociocultural.

Neste contexto, este artigo traz como objetivo expor e discutir as ações de enfermagem com vistas a fortalecer o apego (mãe-bebê-família), aumento da competência da mulher para o seu autocuidado no período puerperal e cuidado do filho recém-nascido. 


\section{METODOLOGIA}

O cenário de atuação do projeto de extensão é a Maternidade do Hospital Universitário Gaffrée e Guinle (HUGG). Nesta maternidade temos 15 leitos de puerpério, 5 leitos de enfermaria de gestantes, 3 leitos de pré-parto e 2 salas de parto. As características das mulheres e adolescentes atendidas de 2010 a 2015 são, em sua maioria, jovens, solteiras, com baixa escolaridade e do lar, que confere um perfil de classe econômica desfavorecida e que quando não bem orientadas retornam precocemente com outra gestação, ou internam por problemas de infecções maternas ou neonatais.

E é com o conhecimento deste perfil que temos como objetivo geral implementar ações de enfermagem com vistas a fortalecer o apego (mãe-bebê-família), aumento da competência da mulher para o seu autocuidado no período puerperal e cuidado do filho recém-nascido. E objetivos específicos:

a) Fortalecer as práticas do manejo do aleitamento materno desde sua instalação, através do estímulo a primeira mamada pós-parto, à manutenção da lactação com apoio e orientações as mães com dificuldade de amamentar, adequando as necessidades da mulher e do recém-nascido.

b) Subsidiar as mães nos cuidados com seu filho recém-nascido (banho, curativo no coto umbilical, higiene oral, troca de fralda, vacinação...).

c) Diminuir as estatísticas de infecção puerperal com orientações sobre cuidados de higiene íntima, com episiorrafia, as fissuras mamárias, ferida operatória; e de desmame precoce, através do estimulo à manutenção da lactação enfatizando sua importância para o binômio mãe-bebê.

d) Empoderar as mulheres para cuidar dos seus filhos no domicílio com perspectivas de aumento das taxas de aleitamento exclusivo;

e) Diminuir a reincidência de gravidez na adolescência e divulgação da prática do sexo seguro, apresentando e orientando sobre planejamento familiar, métodos contraceptivos e onde são ofertados.

f) Preparar as mães e familiares para a alta hospitalar, com vistas ao autocuidado da puérpera e do recém-nascido. 
Atuam no atendimento às mulheres os docentes, discentes voluntários e bolsistas do Projeto. As puérperas são atendidas individualmente e utilizam como instrumento de registro e orientação para as ações dois questionários: um a respeito do aleitamento materno e outro sobre o planejamento familiar. Os questionários contem perguntas que contemplam elementos socioculturais e o conhecimento prévio delas a respeito desse momento do puerpério que está vivenciando, tanto os adquiridos em relações familiares e sociais, como os oferecidos por profissionais de saúde durante o pré-natal.

Após esta primeira entrevista, levantamos onde há déficit no conhecimento e na habilidade para realizar seu autocuidado e do recém-nascido. Com este diagnóstico iniciamos uma ação educativa com a utilização de manequins, com cartilha educativa construída pelos componentes do projeto e até mesmo realizando com elas e não por elas, as práticas de autocuidado e cuidado com seu recém-nascido.

A cartilha oferecida às mulheres foi criada a partir das informações fundamentais ao período puerperal associadas à identificação dos déficits de conhecimento das mulheres assistidas no HUGG relacionados com o cuidado com o seu corpo após o parto, aleitamento materno e cuidado com o bebê (SILVA et al., 2013). 0 material educativo é denominado "Mãe \& Bebê - Pós-parto: orientações para o cuidado no domicílio", contendo 52 páginas ilustradas e que foi financiado pela Agência de Cooperação Internacional do Japão (JICA). Sendo o objetivo da utilização deste material responder às dúvidas mais comuns do dia a dia das puérperas internadas na maternidade e a divulgação com outras mulheres nas comunidades onde vivem.

Na cartilha “Mãe \& Bebê - Pós-parto: orientações para o cuidado no domicílio" são apresentados temas importantes ao cuidado da mulher que está na fase do puerpério e ao cuidado direcionado ao recém-nascido. De forma clara, objetiva e ilustrativa, são apresentados conteúdos como: cuidados à puérpera com a alimentação, o sangramento vaginal, o retorno da atividade sexual pós-parto; as orientações sobre o aleitamento materno e cuidados com a mama; os cuidados com o bebê em domicílio como: orientações relacionada ao sono, regurgitações, higienização do coto umbilical, vacinação, entre outras; e os direitos da mãe, do pai e da criança.

O projeto também implementou a realização de um curso mensal para as gestantes que realizam o pré-natal no HUGG, denominado: "Parto e cuidados com o 
recém-nascido: curso para gestantes e acompanhantes", que objetiva orientar e empoderar a mulher e seu acompanhante - seja ele marido, companheiro, mãe, ou qualquer outro familiar que irá acompanhá-la no momento do parto, para o processo do trabalho de parto e após a alta para ajudar nos cuidados consigo e com seu bebê. 0 primeiro curso será realizado ainda no mês de julho deste ano. Tanto os atendimentos como os cursos são avaliados ao final através de uma escala de satisfação das mulheres, e no caso do curso, também pelos acompanhantes.

Os alunos participam ainda das reuniões do Núcleo de Pesquisa e Experimentação em Enfermagem na Saúde da Mulher e da Criança (NuPEEMC), que acontecem na sede do núcleo na Escola de Enfermagem Alfredo Pinto - UNIRIO. Nelas, são discutidos temas e pesquisas sobre a saúde da mulher e da criança, trazendo novas perspectivas e inovações no atuar da enfermagem para discussão entre os profissionais dessas áreas. 0 que amplia os conhecimentos e estimula o pensamento crítico dos acadêmicos.

\section{DISCUSSÃO E RESULTADOS}

As ações educativas deste projeto de extensão buscam empoderar as mulheres internadas no alojamento conjunto do Hospital Universitário Gaffrée Guinle. Sendo que muitas delas se encontram no período de puerpério imediato, um período de intensa adaptação e insegurança, são entendidas como necessárias as práticas educativas relacionadas ao aleitamento materno, cuidados ao recém-nascido e ao planejamento familiar, que se mostram intensamente relevantes para a promoção da autonomia e confiança das mulheres puérperas. (CEOLIN et al, 2014)

Durante o nosso cuidado identificamos vários valores culturais alinhados a falta de esclarecimento como por exemplos: mulheres que não fazem higiene corporal adequada por não poderem tomar banho de chuveiro, lavarem os cabelos e com isso pode acarretar infecções puerperais ( $3^{\underline{a}}$ causa de morte materna no Brasil), falta de conhecimentos dos benefícios do aleitamento materno e dos malefícios do desmame precoce considerado uma das causas do alto índice de desmame precoce já que as mães não acreditam no poder do leite humano (DIOGO et al, 2011). Muitas das mulheres atendidas não obtiveram nenhuma orientação sobre a amamentação durante o pré-natal, 
sendo ali no alojamento, o primeiro contato com o processo de amamentação e suas orientações.

As atividades realizadas no alojamento conjunto são de forma individualizada, onde se examinam as mamas e o processo de amamentação, e os conhecimentos e dúvidas das puérperas sobre o aleitamento materno e planejamento familiar. 0 exame das mamas tem como objetivo identificar a forma e tamanho das mamas, conformação e integridade dos mamilos, assim, reconhecendo qualquer sinal físico que possa interferir negativamente na amamentação. À todas as puérperas são realizadas orientações gerais sobre amamentação e seus cuidados, cuidados ao recém-nascido e planejamento familiar.

As mulheres que apresentam dificuldades para amamentar, sejam por "baixa produção de leite", "leite empedrado" ou por práticas inadequadas, recebem atenção e orientações mais incisivas e específicas. São orientadas e ensinadas a realizarem massagem e ordenha manual apropriadas das mamas; orientadas ao uso correto de sutiãs, mamada por livre demanda entre outras orientações de acordo com a especificidade. As mulheres que estão em processo doloroso e/ou com presença de fissuras mamilares, são estimuladas à realização da pega correta, da soltura adequada do mamilo pelo bebe, da utilização do leite materno como agente cicatrizador e hidratante, maior atenção a higienização das mãos durante a manipulação das mamas e manutenção do uso de sutiãs limpos.

Em outra etapa, foram dadas às puérperas atendidas espaço para expressar experiências, dúvidas, anseios e desejos sobre o planejamento familiar e métodos contraceptivos. As mulheres apresentam muitas dúvidas em relação ao início da atividade sexual e quais métodos podem usar. Algumas já apresentavam preferências em determinados métodos para o uso pós-gravidez como pílula anticoncepcional, camisinha masculina, dispositivo intrauterino (DIU) e laqueadura. Foram orientadas quanto aos tipos de métodos contraceptivos, suas vantagens e desvantagens, eficácia e sua oferta nas unidades de saúde.

Após a execução das orientações, é dada a cada mulher uma folha de avaliação onde sinalizam a satisfação com o atendimento realizado pelas bolsistas. São avaliadas as informações transmitidas, o local do atendimento, a didática utilizada nas orientações 
e como elas avaliam a aplicabilidade das orientações no dia-a-dia.

As atividades demostraram a importância de um olhar atento que valorize aspectos emocionais, a cultura familiar, social e entre outros. Necessariamente reconhecendo a mulher como protagonista do seu processo de amamentar, valorizandoa, escutando-a e empoderando-a e, então, prestando cuidados eficazes ao binômio mãe/bebê e sua família.

Durante o atendimento, as mulheres se mostraram satisfeitas, com as orientações obtidas, adotando postura participativa no decorrer da prática, pretendendo demostrar os conteúdos adquiridos e mostrando otimismo e entusiasmo na aplicabilidade dos mesmos no processo de amamentação. Por fim, destaca-se que o momento da internação é importante para que as práticas educativas sejam efetuadas, quebrando a rotina do setor, incentivando o aprendizado dos cuidados, sendo perceptível a maior autonomia e segurança que as mulheres demonstraram em relação ao autocuidado e cuidado ao recém-nascido.

\section{CONCLUSÃO}

A atuação do projeto de extensão "Espaço Educativo para o Cuidado de Mãe e Bebê" no atendimento individual no Hospital Universitário Gaffrée e Guinle, com implementação de curso mensal para gestantes e acompanhantes afim de melhor prepara-los para o parto e pós-parto, e treinamento da equipe de saúde da maternidade permite uma atuação abrangente com resultados positivos na saúde da mulher e neonatal. Esses resultados são evidenciados quando observamos maior sucesso na amamentação, diminuição pela instituição de compra de leite industrializado para os recém-nascidos, diminuição do período de internação, menor retorno com problemas na amamentação e por gravidez indesejada, por fim as mulheres mais seguras e autônomas, refletindo na saúde do bebê e da família.

\section{REFERÊNCIAS}

ACOSTA, D.F. et al. Influências, crenças e práticas no autocuidado das puérperas. Revista da Escola de Enfermagem da USP, v. 46, n. 6, ano 2012. 
BRASIL, Ministério da Saúde. Atenção à saúde do recém-nascido: guia para os profissionais de saúde - Cuidados gerais. Brasília: Ministério da Saúde; 2014.

BRASIL. Presidência da República. Lei no 8.069, de 13 de Julho. Ministério da Saúde, Brasília, DF, 1990. Disponível em http://www.planalto.gov.br/ccivil_03/leis/L8069.htm . Acesso em: 14 jun. 2016.

CEOLIN, R.; DA ROSA, L.; POTRICH, T.; ZANATTA, E.. Educação em saúde como ferramenta para uma atenção integral à saúde da mulher: Uma reflexão teórica. Disponível

em: http://www.revistas.fw.uri.br/index.php/revistadeenfermagem/article/view/1141/161 9 Acesso em: 17 Maio 2016.

COSTA, N. S et al. Prática do autocuidado e demandas por cuidados de enfermagem pelas puérperas. Revista de Enfermagem e Atenção à Saúde, v. 2, n. 1, ano 2013, p. 75-88.

DIOGO, E. F.; SOUZA, T.; ZOCCHE, Denise. Causas do desmame precoce e suas interfaces com a condição socioeconômica e escolaridade. Enfermagem em Foco; v. 2, n. 1, ano 2011, p. 10-13.

MIRANDA, D. B.; MAROSTICA, F. C.; LIÉGIO, M. E. Influência do fator cultural no processo de cuidado puerperal. Revista Eletrônica Gestão \& Saúde, v. 6, n. 3, ano 2015, p. 24442459.

PEREIRA, M. C; GRADIM, C. V. C. Consulta puerperal: A visão do enfermeiro e da puérpera. Revista Ciência, cuidado e saúde, v. 13, n.1, ano 2014, p. 35-42.

SILVA, Leila R. et al. Cartilha Mãe \& Bebê - Pós-parto: orientações para o cuidado no domicílio. Pró-Reitoria de Extensão e Cultura. Universidade Federal do Estado do Rio de Janeiro; 2013.

SILVA, L. R. et al. Enfermagem no puerpério: Detectando o conhecimento das puérperas para o autocuidado. Revista de pesquisa: Cuidado é fundamental online, v. 4, n. 2, ano 2012, p .2327-37. 
O puerpério como espaço educativo para o cuidado mãe e bebê

The puerperium as an educational space for mother and baby care

Abstract: This experience report aims to present and discuss the nursing actions in order to increase women's skills for self-care in the postpartum period and newborn child care. The target population of this project, which are the women admitted to rooming University Hospital Gaffrée and Guinle was employee interviews focusing on women's knowledge of puerperal and held practices of individual and collective educational actions process. Obtained main results greater success in breastfeeding, decreased by industrialized milk purchasing institution for newborns, decreased hospital stay, lower return with breastfeeding problems and unwanted pregnancies. We conclude that individualized care that values emotional and socio-cultural aspects of postpartum women, that become protagonists of their own care reflected in your health, baby and family.

Key-words: Puerperium. Health education. Obstetric nursing.

\section{El puerperio como espacio educativo para el cuidado de la madre y del bebé}

Resumen: Este relato de experiencia tiene como objetivo presentar y discutir las acciones de enfermería con el fin de aumentar la capacidad de la mujer para el autocuidado en el período post-parto y el cuidado de niños recién nacidos. La población objetivo de este proyecto, que son las mujeres admitidas en el alojamiento conjunto del Hospital Universitario Gaffrée y Guinle fue entrevistas a los empleados que se centran en el conocimiento de las mujeres sobre las prácticas puerperales y en poder de las acciones proceso educativo individual y colectivo. principales resultados obtenidos mayor éxito en la lactancia materna, la disminución por institución industrializado pago de la leche para los recién nacidos, la disminución de la estancia hospitalaria, menor de retorno con problemas de lactancia materna y embarazos no deseados. Llegamos a la conclusión de que la atención individualizada que valora los aspectos emocionales y socio-culturales de las mujeres después del parto, que se convierten en protagonistas de su propio cuidado se refleja en su salud, el bebé y la familia.

Palabras clave: Puerperio. Educación para la salud. Enfermería obstétrica.

Original submetido em: 18 nov. 2016

Aceito para publicação em: 09 jan. 2017

\section{Sobre os autores:}

\section{Cristiane Rodrigues da Rocha}

Departamento de Enfermagem Materno-Infantil, Universidade Federal do Estado do Rio de Janeiro. Especialista em Enfermagem Obstétrica. Doutora em Enfermagem.

\section{Inês Maria Meneses dos Santos}

Departamento de Enfermagem Materno-Infantil, Universidade Federal do Estado do Rio de Janeiro. Enfermeira Obstétrica. Doutora em Enfermagem. 


\section{Isabeli Fragoso da Conceição}

Bolsista de Extensão da UNIRIO. Estudante de Graduação em Enfermagem, Escola de Enfermagem Alfredo Pinto, Universidade Federal do Estado do Rio de Janeiro.

\section{Leila Rangel da Silva}

Departamento de Enfermagem Materno-Infantil, Universidade Federal do Estado do Rio de Janeiro. Enfermeira Obstétrica. Pós-doutora em Enfermagem.

\section{Mayara Tereza de Carvalho}

Bolsista de Extensão da UNIRIO. Estudante de Graduação em Enfermagem, Escola de Enfermagem Alfredo Pinto, Universidade Federal do Estado do Rio de Janeiro. 